\title{
Multivariate Optimization Applied to Chromium Determination in Milk and Similar Baby Food Samples by Graphite Furnace Atomic Absorption Spectrometry
}

\author{
Flávia Regina de Amorima ${ }^{a}$, Eliana Aparecida Nonato Knupp ${ }^{\mathrm{b}}$, José Bento Borba da Silva ${ }^{\mathrm{c}, *}$, \\ and Clésia Cristina Nascentes ${ }^{\mathrm{c}}$ \\ ${ }^{a}$ Department of Chemistry, Institute of Chemistry, Federal University of Uberlândia, \\ 38400-902, Uberlândia, MG, Brazil \\ ${ }^{\text {b }}$ Centro de Desenvolvimento da Tecnologia Nuclear, Comissão Nacional de Energia Nuclear, \\ 31270-901, Belo Horizonte, MG, Brazil \\ c* Department of Chemistry, Institute of Exact Sciences, Federal University of Minas Gerais, \\ 31270-901, Belo Horizonte, MG, Brazil
}

\section{INTRODUCTION}

Food fortification is important in combating nutritional deficiencies. Moreover, processing steps, fortification, and the existence of various formulations employing different components as raw materials increase the possibility of undesirable elements in the final product. Furthermore, the interaction between constituents of foods must be evaluated because excessive addition of some nutrients may lead to the disability of others which can become extremely harmful. In this respect, infant foods deserve special attention because they are essential for developing the immune system. Thus, proper quality control of these food products is of great importance. In this context, the quantification of inorganic constituents in foods is required in order to monitor the levels of toxic and essential elements and to ensure maintenance of the quality of the food. In food analysis, sample preparation is a critical step and can consume up to $80 \%$ of the total time spent with the analysis (1). Traditional methods for preparing baby food samples includes wet or dry digestion processing (2), microwave-assisted digestion (3-5), lyophilization and ashing of the samples (6). However, these conventional methods have some disadvantages such as the high

Corresponding autbor.

E-mail: bentojb@yaboo.com.br

Tel: +553134095708

\section{ABSTRACT}

Chromium (Cr) is an essential element, but high levels in foods can be toxic particularly for children. A fast and efficient method to determine $\mathrm{Cr}$ in milk and other infant foods using slurries and liquid samples is presented. Slurries were prepared in ultrapure water with 10 minutes of sonication. The liquid samples were diluted in ultrapure water when necessary. Multivariate optimization was used to establish some optimal analytical parameters through a fractional factorial design and a central composite design. Slurried and diluted samples were analyzed directly by GFAAS. The method presented a limit of detection of $1.43 \mu \mathrm{g} \mathrm{L}^{-1}$, characteristic mass of $4.5 \mathrm{pg}$ (recommended value of $3.0 \mathrm{pg}$ ), RSD from 1.5 to $11.8 \%(n=8)$, and a linear range from 4.78 to 50.0 $\mu \mathrm{g} \mathrm{L}^{-1}$ using rhodium $(500 \mu \mathrm{g})$ as the permanent modifier. The accuracy was evaluated by analyzing standard reference material SRM 8435 Whole Milk Powder. Good agreement was found with the obtained and certified values. The $\mathrm{Cr}$ concentrations of the powdered samples were between 0.042 and 1.900 $\mu \mathrm{g} \mathrm{g}^{-1}$.

possibility of loss of volatile elements and contamination, poorer detection limits due to dilution of the samples, time-consuming and often very costly $(7,8)$. On the other hand, there are some alternatives for the preparation of samples that minimizes the drawbacks of decomposition such as direct introduction of the sample after solubilization, dilution or slurry preparation (9). The effectiveness of these procedures often depends on the type of food, the analytes and the employed analytical technique. There is, therefore, a need to develop faster methods with high accuracy and precision, where the losses and contamination are minimized and direct analysis or preparation is possible in a few steps.

The fact that chromium (Cr) is an essential mineral was first demonstrated by Mertz in 1969 (10) in rats and the importance of $\mathrm{Cr}$ in humans was demonstrated by Jeejebhoy et al. in 1977 (11). In the years following, a number of papers on the impact of $\mathrm{Cr}$ in human nutrition during different clinical and stress situations were published (12-17) with the main focus on the association between $\mathrm{Cr}$ and diabetes mellitus for type 2 diabetes (18). A number of animal trials were performed as well $(19,20)$. It was not until the 1990s that $\mathrm{Cr}$ also started to be studied intensively as an essential mineral in livestock (cattle, sheep, horses, pigs, and poultry) (21).

The association between $\mathrm{Cr}$ and carbohydrate metabolism has been demonstrated by trials involving livestock fed parenteral nutrition (21). The total amount of $\mathrm{Cr}$ in the human body ranges from 0.4 to 6.0 $\mathrm{mg}$. The $\mathrm{Cr}$ reserve relative to body 
weight is higher in newborn children in comparison to adults (22). Numerous studies show evidence that $\mathrm{Cr}$ is essential for the lipid metabolism and reduces the risk of atheroenesis. It is assumed that the activity of $\mathrm{Cr}$ is mediated by the anabolic action of insulin, but other mechanisms cannot be ruled out. Chromium acts as a cofactor for insulin and, therefore, Cr activity in the organism is parallel to the functions of insulin. Despite its ability to enhance insulin activity, $\mathrm{Cr}$ cannot substitute for insulin (21). A number of studies confirm the association between $\mathrm{Cr}$ and the metabolism during increased physiological, pathological, and nutritional stress, e.g., fatigue, trauma, gestation, and different forms of nutritional (high carbohydrate diet), metabolic, physical, and emotional stress as well as environmental effects (23).

The average concentration of $\mathrm{Cr}$ in human milk is reported to be below $0.4 \mu \mathrm{g} \mathrm{L}^{-1}$ (24-25). However, in a study performed with Brazilian mothers from Belo Horizonte (MGBrazil), the Cr concentration in breast milk varied from 0.69 to $17.3 \mu \mathrm{g} \mathrm{L}^{-1}$ (26). The recommended daily allowance as established in 1989 by the Food and Nutrition Board of the National Research Council, Canada (27) is an intake of $750 \mathrm{~mL}$ of milk from milk formulas and other foods. A range of $\mathrm{Cr}$ intake from 50 to $200 \mu \mathrm{g} /$ day is tentatively recommended for adults. Casey et al. (25) reported that the Estimated Safe and Adequate Daily Dietary Intake (ESADDI) for infants from the age of 0 to 6 months is 10 to $40 \mu \mathrm{g} \mathrm{Cr} / \mathrm{day}$.

In this context, a method for the determination of $\mathrm{Cr}$ in whole milk, skim milk, milk beverage, infant formula, soy-based formula, goat's milk, and mother's milk by graphite furnace atomic absorption spectrometry (GFAAS), without sample pretreatment, was developed.

\section{EXPERIMENTAL}

\section{Instrumentation}

In this study, a PerkinElmer ${ }^{\circledR}$ model AAnalyst ${ }^{\mathrm{TM}} 400$ atomic absorption spectrometer was used, equipped with an HGA®-800 graphite furnace, background correction with a deuterium lamp, and an AS-800 autosampler (PerkinElmer, Inc., Shelton, CT, USA). The readings were made using integrated absorbance (peak area). A PerkinElmer Lumina ${ }^{\circledR}$ hollow cathode lamp (HCL) of Cr was used, operating under the conditions as recommended by the manufacturer. A hollow cathode lamp for Cr (PerkinElmer Part No. N3050119) was employed using a current of $30 \mathrm{~mA}$, slit width of $0.2 \mathrm{~nm}$, and wavelength of $357.9 \mathrm{~nm}$.

\section{Reagents, Solutions and Certified Reference Material}

Deionized water (resistivity of 18.2 $\mathrm{M} \Omega \cdot \mathrm{cm}^{-1}$ ) was obtained with a Milli-Q ${ }^{\mathrm{TM}}$ system (Millipore Corporation, Bedford, MA, USA) and purified immediately before preparation of the solutions. Nitric acid was obtained from Merck (Darmstadt, Germany). Solutions (1000 $\mathrm{mg} \mathrm{L}^{-1}$ ) of iridium, ruthenium, and rhodium were obtained from Fluka (Buchs, Switzerland) and used at $1 \mathrm{~mol} \mathrm{~L}^{-1}$ in hydrochloric acid. Tungsten in the same solution was acquired from Merck (Titrisol ${ }^{\circledR}$, Merck).

Plastic bottles, autosampler cups, and glassware were cleaned by soaking in $20 \%(\mathrm{v} / \mathrm{v}) \mathrm{HNO}_{3}$ for one day, rinsing many times with Milli-Q water, and then dried. The autosampler washing solution, containing $0.05 \%(\mathrm{v} / \mathrm{v})$ Triton ${ }^{\circledR} \mathrm{X}-100$ (Merck) plus 0.1\% (v/v) isopropanol (Sigma-Aldrich, São Paulo, Brazil), was used to avoid analyte adsorption onto the surface of the container and clogging of the capillary sampling tip, as well as to improve dispersion of the sample solution onto the platform.

\section{A $_{\text {Somic }}^{\text {tomict(6), Low Doc } 20.2016}$}

Chromium stock solutions (1000 $\mathrm{mg} \mathrm{L}^{-1}$ ) were prepared from Titrisol ${ }^{\circledR}$ (Merck) in 5\% (v/v) nitric acid.

A standard certified material NIST SRM Whole Milk Powder (National Institute of Standards and Technology, Gaithersburg, MD, USA) was used to check for accuracy of the method.

\section{Graphite Tube Treatment}

The graphite tubes were treated independently with $500 \mu \mathrm{g}$ of each studied permanent modifier (Ir, Rh, Ru) by applying $50 \mu \mathrm{L}$ of each metal solution (1000 $\left.\mathrm{mg} \mathrm{L}^{-1}\right)$ onto the wall of the tube and submitting them 10 times to a furnace temperature program as previously described (28).

\section{Optimization Strategies}

For choosing the most appropriate permanent modifier, various measures were carried out in integrated absorbance and using the background signal ratio in accordance with the manufacturer's recommended conditions. Thus, $20 \mu \mathrm{L}$ of whole milk diluted $1+1$ with deionized water were injected into the graphite tube treated with the permanent modifiers $(\mathrm{W}, \mathrm{Ru}, \mathrm{Rh}$, Ir), and also in a tube without modifier. The CTAC (Cetyltrimethylammonium chloride) reagent of $0.1 \%$ $(\mathrm{v} / \mathrm{v})$ was used to prevent formation of carbonaceous residues (2931).

In all optimization steps, $20 \mu \mathrm{L}$ of the prepared slurry was used. A sample of liquid whole milk diluted $1+1$ and spiked with $30 \mu \mathrm{g} \mathrm{L}^{-1} \mathrm{Cr}$ was used since in the initial studies, using the heating program recommended by the manufacturer, the obtained analytical signal was not satisfactory. Initially, a $2^{3-1}$ fractional factorial design was carried out in order to investigate the influence of the main variables involved in the $\mathrm{Cr}$ determination process by GFAAS such as pyrolysis and atom- 
ization temperatures and pyrolysis time (Table I). Based on these results, a central composite design (CCD) was applied (Table II), using the significant variables and the Statistica 6.1 software (Statsoft, Inc. / Dell, Inc., USA) (32).

\section{Parameters of Merit}

For the studies on matrix effects, the samples were divided into groups according to type. For each group, a sample was prepared by mixing equal volumes of each sample belonging to the group.

Group 1: Samples of whole milk powder, total of 5 samples (composite sample A1).

Group 2: Samples of skimmed milk powder, infant formulas and enriched, total of 5 samples (composite sample A2).

Group 3: Dairy drink powder samples, total of 2 samples (composite sample A3).

Group 4: Liquid skimmed milk samples, total of 7 samples (composite sample A4).

Group 5: Powdered soybean food sample total of 1 sample (composite sample A5).

Group 6: Samples of liquid soybean meal, total of 2 samples (composite sample A6).

Then, aqueous calibration curves were constructed ( 0 to $50 \mu \mathrm{g} \mathrm{L}^{-1}$ ) and the standard addition curves (0 to $50 \mathrm{ug} \mathrm{L}^{-1}$ ) in each composite sample were made to verify the performance of the optimized method and also to study the matrix effects. Linearity was assessed by linear correlation coefficients. The characteristic mass was obtained through the aqueous calibration curve. The limits of detection and quantification were calculated according to IUPAC ( $n=10$ and parameters of the aqueous curve). The precision (repeatability) was evaluated with 8 replicate solutions in 3 different concentrations: 5,10 , and $20 \mu \mathrm{g} \mathrm{L}^{-1}$. The accuracy was checked by analysis of the certified reference material NIST SRM 8435 Whole Milk Powder. Its preparation consisted of dissolution in deionized water and analysis against the aqueous curve.

\section{RESULTS AND DISCUSSION}

\section{Optimization of the Experimen- tal Conditions}

Three permanent modifiers showing satisfactory results in the study were: W, Rh, and Ru. Since Rh showed higher sensitivity and low background absorption, this modifier was chosen for further studies.
The results of the fractional factorial design can be seen Table III. Analyzing the Pareto chart (Figure 1), it can be seen that all variables were significant at the 95\% confidence level. The results obtained in the fractional factorial design were employed to optimize the method for the determination of $\mathrm{Cr}$ in milk and similar products by GFAAS.

The individual effect of these variables was positive for time and atomization. This suggests an increase in the values of these variables to obtain maximum response (integrated absorbance), unlike the pyrolysis temperature (PT), which showed significant negative effects, suggesting a decrease of PT to achieve the maximum response.

TABLE I

Concentration Levels Studied Using Fractional Factorial Design (2 (3-1) $^{3}$ in Optimizing the Method for the GFAAS Determination of Cr in Milk and Similar Baby Foods

\begin{tabular}{lcc}
\hline Variable & Low Level $(-1)$ & High Level $(+1)$ \\
\hline Pyrolysis temperature $(\mathrm{PT})\left({ }^{\circ} \mathrm{C}\right)$ & 1300 & 1900 \\
Atomization temperature $(\mathrm{AT})\left({ }^{\circ} \mathrm{C}\right)$ & 2000 & 2600 \\
Pyrolysis time $(t)(\mathrm{s})$ & 30 & 50 \\
\hline
\end{tabular}

TABLE II

Concentration Levels Studied in CCD Using the Optimization Method for GFAAS Determination of $\mathrm{Cr}$ in Milk and Similar Baby Foods

\begin{tabular}{cl}
\hline Factors & Evaluated Levels \\
\hline TP & $1095^{\circ} \mathrm{C}(-\sqrt{3}), 1300(-1), 1600(0), 1900(+1), 2105(\sqrt{ } 3)$ \\
TA & $1795^{\circ} \mathrm{C}(-\sqrt{3}), 2000(-1), 2300(0), 2600(+1), 2805(\sqrt{ } 3)$ \\
$t$ & $6(-\sqrt{3}), 20(-1), 40(0), 60(+1), 74(\sqrt{ } 3)$ \\
\hline
\end{tabular}

TABLE III

Factorial Planning for GFAAS Determination of $\mathrm{Cr}$ in Milk and Similar Baby Foods Using Ru as Permanent Modifier

\begin{tabular}{clllc}
\hline Test & PT $\left({ }^{\circ} \mathrm{C}\right)$ & AT $\left({ }^{\circ} \mathrm{C}\right)$ & T $(\mathrm{s})$ & $\begin{array}{c}\text { Integrated Absorbance }\left(\mathrm{A} \mathrm{s}^{-1}\right) \\
\text { Average } \pm \mathrm{s}(\mathrm{n}=3)\end{array}$ \\
\hline 1 & $1300(-1)$ & $2000(-1)$ & $50(+1)$ & $0.260 \pm 0.026$ \\
2 & $1300(-1)$ & $2600(+1)$ & $30(-1)$ & $0.283 \pm 0.010$ \\
3 & $1900(+1)$ & $2000(-1)$ & $30(-1)$ & $0.018 \pm 0.002$ \\
4 & $1900(+1)$ & $2600(+1)$ & $50(+1)$ & $0.080 \pm 0.006$ \\
\hline
\end{tabular}

The values in parentheses correspond to the encoded value. 
From the results obtained in the fractional factorial design, a central composite design (CCD) was constructed to verify the optimum conditions for the determination of $\mathrm{Cr}$ in different milks and similar baby foods. The results of the CCD can be viewed in Table IV. Analyzing the Pareto chart obtained by the $\mathrm{CCD}$, one can see that all variables were significant at a confidence level of $95 \%$ as well as the interactions between them (Figure 2). The PT and time of pyrolysis $(t)$ variables had significant negative effects, suggesting a higher response when evaluating the $\mathrm{PT}$ and $t$ at lower levels, unlike the atomization temperature (AT), which showed significant and positive effects, suggesting an increase of AT leads to a better response. The interaction between AT and PT had a significantly positive effect, suggesting an increase in response when working simultaneously at the lower level of PT and the higher level of AT. There is a significant negative effect on the interactions between $t$ and PT and between $t$ and AT, while the quadratic interaction of $t$ had a signifi- cant positive effect. There is a significant negative effect on the interaction between $t$ and PT and between $t$ and AT, while the qua-

\section{Atomic Spectroscopy \\ 1 Vol. 37(6), Nov./Dec. 2016}

dratic interaction of $t$ had a significant positive effect.

\section{TABLE IV}

Results of Central Composite Design Optimization in the GFAAS Determination of $\mathrm{Cr}$ in Milk and Similar Baby Foods

\begin{tabular}{cllll}
\hline Test & PT $\left({ }^{\circ} \mathrm{C}\right)$ & AT $\left({ }^{\circ} \mathrm{C}\right)$ & $t(\mathrm{~s})$ & $\begin{array}{c}\text { Integrated Abs. }\left(\mathrm{A} \mathrm{s}^{-1}\right) \\
\text { Average } \pm \mathrm{s}(\mathrm{n}=2)\end{array}$ \\
\hline 1 & $1095(-\sqrt{3})$ & $2300(0)$, & $40(0)$ & $0.860 \pm 0.023$ \\
2 & $1300(-1)$ & $2000(-1)$ & $20(-1)$ & $0.760 \pm 0.007$ \\
3 & $1300(-1)$, & $2000(-1)$ & $60(+1)$ & $0.731 \pm 0.028$ \\
4 & $1300(-1)$, & $2600(+1)$ & $20(-1)$ & $0.929 \pm 0.006$ \\
5 & $1300(-1)$, & $2600(+1)$ & $60(+1)$ & $0.923 \pm 0.012$ \\
6 & $1600(0)$ & $1795(-\sqrt{3})$ & $40(0)$ & $0.062 \pm 0.083$ \\
7 & $1600(0)$ & $2300(0)$ & $6(-\sqrt{ } 3)$ & $1.146 \pm 0.198$ \\
8 & $1600(0)$ & $2300(0)$, & $40(0)$ & $0.776 \pm 0.017^{\mathrm{a}}$ \\
9 & $1600(0)$ & $2300(0)$, & $74(\sqrt{3})$ & $0.657 \pm 0.000$ \\
10 & $1600(0)$ & $2805(\sqrt{3})$ & $40(0)$ & $0.997 \pm 0.030$ \\
11 & $1900(+1)$ & $2000(-1)$ & $20(-1)$ & $0.287 \pm 0.001$ \\
12 & $1900(+1)$ & $2000(-1)$ & $60(+1)$ & $0.071 \pm 0.009$ \\
13 & $1900(+1)$ & $2600(+1)$ & $20(-1)$ & $0.762 \pm 0.055$ \\
14 & $1900(+1)$ & $2600(+1)$ & $60(+1)$ & $0.256 \pm 0.054$ \\
15 & $2105(\sqrt{3})$ & $2300(0)$, & $40(0)$ & $-0.001 \pm 0.004$
\end{tabular}

${ }^{\text {a }}$ Five replicates were performed at the midpoint. The figures in brackets refer to the coded values.

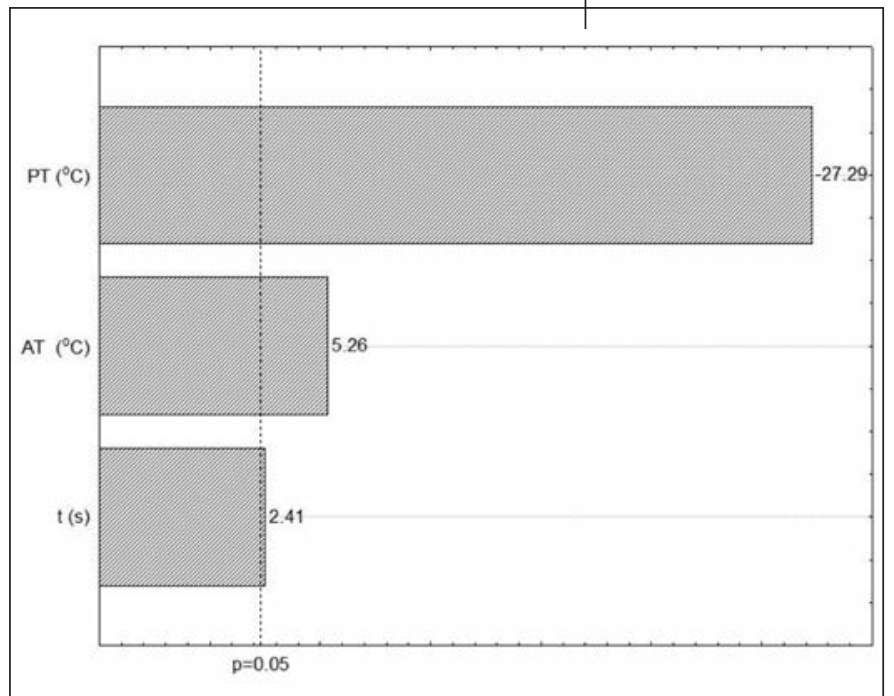

Fig. 1. Pareto chart obtained with the fractional factorial design.

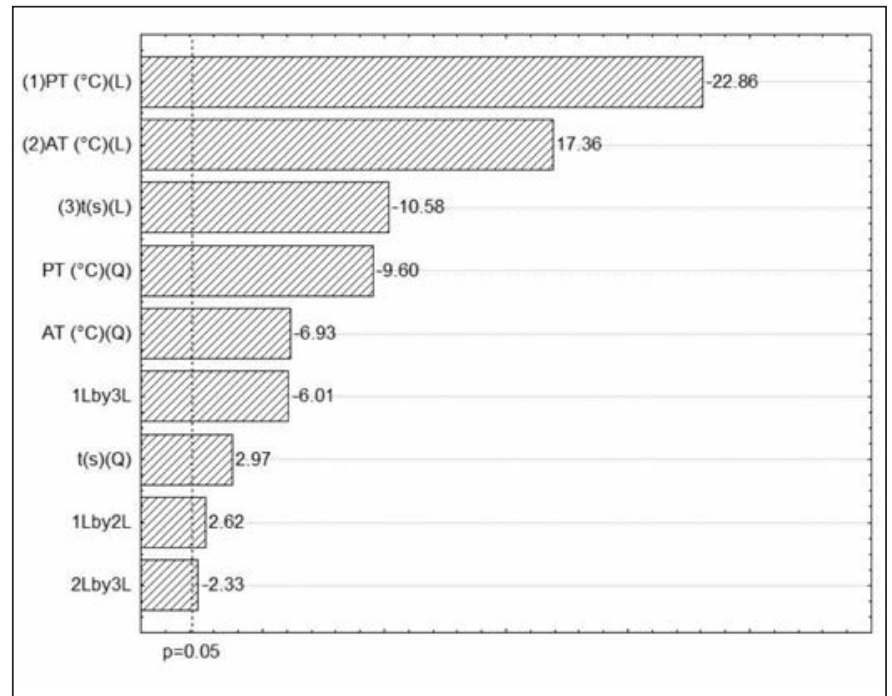

Fig. 2. Pareto chart obtained with the CCD, showing the estimated effect of the variables: PT, pyrolysis temperature; $A T$, atomization; $t$, pyrolysis time, $Q$, quadratic interaction, L-linear interaction. 
The quadratic model obtained from the CCD is expressed according to the following equation:

$\mathrm{A}=7.8894+\left(3.3163 \times 10^{-3}\right)$ $(\mathrm{PT})-\left(1.4166 \times 10^{-6}\right)(\mathrm{PT})^{2}+$ $\left(4,8945 \times 10^{-3}\right)(\mathrm{AT})-1.02285 \times$ $\left.10^{-6}\right)(\mathrm{AT})^{2}+\left(4.1597 \times 10^{-7}\right)(\mathrm{PT})$ (AT) $-\left(1.432291 \times 10^{-3}\right)(\mathrm{PT})(t)$ $-\left(5.552083 \times 10^{-6}\right)(\mathrm{AT})(t)$

where $\mathrm{A}$ is the absorbance integrated response, $\mathrm{PT}$ is the pyrolysis temperature, AT is the atomization temperature, and $t$ is time of pyrolysis.

The critical point was calculated from the partial derivatives $[\partial \mathrm{A} / \partial$ $(\mathrm{PT})]=1277^{\circ} \mathrm{C},[\partial \mathrm{A} / \partial(\mathrm{AT})]=$ $2512{ }^{\circ} \mathrm{C}$ and $[\partial \mathrm{A} / \partial(t)]=52 \mathrm{~s}$, corresponding to the region with greater sensitivity. The maximum,

TABLE V

Points Observed by CCD in the Optimization Method for the GFAAS Determination of $\mathrm{Cr}$ in Milk and Similar Baby Foods

\begin{tabular}{lccc}
\hline Parameters & $\begin{array}{c}\text { Minimum } \\
\text { Observed }\end{array}$ & $\begin{array}{c}\text { Critical } \\
\text { Point }\end{array}$ & $\begin{array}{c}\text { Maximum } \\
\text { Observed }\end{array}$ \\
\hline Pyrolysis Temp. $\left({ }^{\circ} \mathrm{C}\right)$ & 1095 & 1277 & 2105 \\
Atomization Temp. $\left({ }^{\circ} \mathrm{C}\right)$ & 1795 & 2512 & 2805 \\
Pyrolysis Time $(\mathrm{s})$ & 6 & 52 & 74 \\
\hline
\end{tabular}

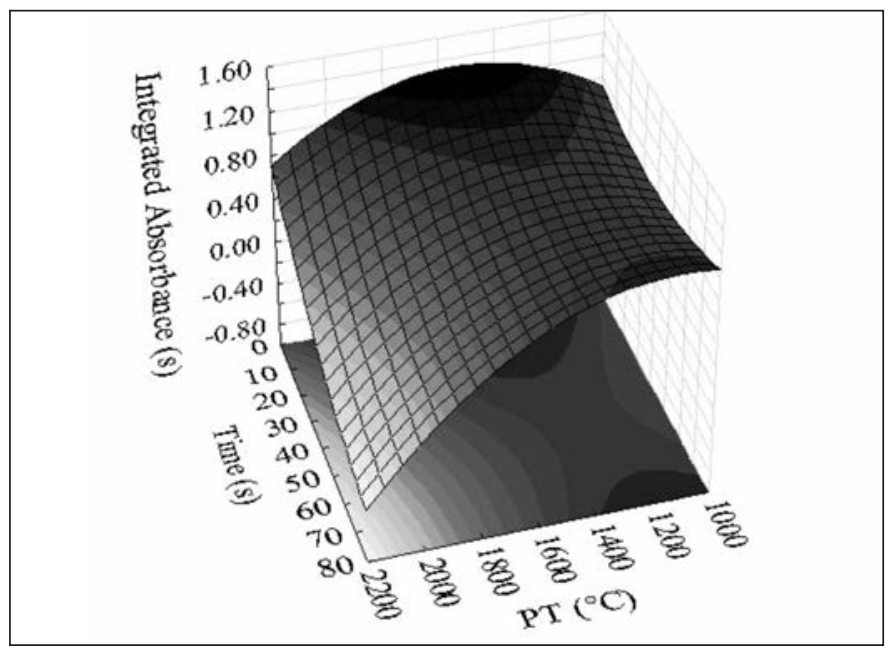

Fig. 4. Response surface and the contours obtained by the CCD fixing the atomization temperature at $2512{ }^{\circ} \mathrm{C}$. minimum, and critical points are presented in Table V. For visualization of the response surface, it was necessary to set a variable obtained conditions, the background absorpwas properly corrected.

Thus, the optimal experimental conditions for determining $\mathrm{Cr}$ in different milks and similar baby foods have been established: Rh as permanent modifier, pyrolysis temperature of $1280{ }^{\circ} \mathrm{C}$, atomization temperature of $2510^{\circ} \mathrm{C}$, and pyrolysis time of 52 seconds.

\section{Figures of Merit}

Using the above optimized method, the performance characteristics were determined.

The results obtained in the study of matrix effects are listed in Table VI. The samples were grouped according to similarity and composite samples were prepared. Comparing the slopes of the curves 
performed in conditions of repeatability, it can be seen that the slopes of the standard addition curves A2, A4, A5, and A6 are statistically similar to the slope of the aqueous curves (95\% confidence level). This suggests the use of aqueous calibration for the determination of $\mathrm{Cr}$ in whole milk samples, skimmed milk, infant formulas and enriched powder, liquid skimmed milk and the powder, and liquid soybean meal samples since there is no matrix effect on the analytical signal. For other types of matrices, standard addition calibration should be used to obtain more accurate results. The other analytical parameters of merit were obtained based on aqueous calibration (Table VII).

The linear working range was established between the limit of quantification and the last point of the calibration curve. The limit of detection $\left(1.43 \pm 0: 09 \mu \mathrm{g} \mathrm{L}^{-1}\right)$ and the limit of quantification $(4.78 \pm$ $0.29 \mathrm{ug} \mathrm{L}^{-1}$ ) were calculated by the IUPAC criterion, according to LOD

TABLE VI

Calibration Results Through the Standard Addition Calibration Curves for the Composite Samples and the Aqueous Curve for Evaluating the Matrix Effect in Determining $\mathrm{Cr}$ in Milk and Similar Foods by the Optimized GFAAS Method

\begin{tabular}{cccccc}
\hline \multicolumn{3}{c}{ Standard Addition Calibration Curves } & \multicolumn{3}{c}{ Aqueous Calibration Curves } \\
\hline \multicolumn{3}{c}{$\begin{array}{c}\text { Slope and Deviation } \\
\text { Obtained by } \\
\text { Regression }\end{array}$} & $\mathrm{r}$ & $\begin{array}{c}\text { Slope and Deviation } \\
\text { Obtained by } \\
\text { Regression }\end{array}$ & $\mathrm{r}$ \\
\hline A1 & $0.0210 \pm 0.0013$ & 0.9964 & $0.0182 \pm 0.0002$ & 0.9993 \\
A2 & $0.0175 \pm 0.0001$ & 1.0000 & $0.0182 \pm 0.0002$ & 0.9993 \\
A3 & $0.0215 \pm 0.0024$ & 0.9993 & $0.0182 \pm 0.0002$ & 0.9993 \\
A4 & $0.0177 \pm 0.0012$ & 0.9951 & $0.0182 \pm 0.0002$ & 0.9993 \\
A6 & $0.0166 \pm 0.0006$ & 0.9985 & $0.0158 \pm 0.0005$ & 0.9987 \\
A7 & $0.0169 \pm 0.0004$ & 0.9995 & $0.0156 \pm 0.0002$ & 0.9993 \\
\hline
\end{tabular}

a Aqueous curves obtained from repeatability conditions relative to the correspond ing standard addition curves.

TABLE VII

Performance Characteristics of the Optimized Method for GFAAS Determination of $\mathrm{Cr}$ in Milk and Similar Baby Foods

\begin{tabular}{ll}
\hline Parameters & Results \\
\hline Linear working range & $4.78-50.00 \mu \mathrm{g} \mathrm{L}^{-1}$ \\
Limit of detection, LOD & $1.43 \pm 0.09 \mu \mathrm{g} \mathrm{L}^{-1}$ \\
Limit of detection, LOD & $28.6 \pm 1.8 \mu \mathrm{g} \mathrm{kg}^{-1}$ \\
Limit of quantification, LOQ & $4.78 \pm 0.29 \mu \mathrm{g} \mathrm{L}^{-1}$ \\
Limit of quantification, LOQ $^{\text {Precision, RSD }}$ & $95.6 \pm 5.8 \mu \mathrm{g} \mathrm{kg}^{-1}$ \\
Accuracy (SRM 8435) $_{\text {Recovery }}^{\mathrm{c}}$ & 1.5 to $11.8 \%$ \\
Characteristic mass $^{\mathrm{c}}$ & $0.461 \pm 0.035^{\mathrm{b}} \mu \mathrm{g} \mathrm{g}^{-1}$ \\
\hline
\end{tabular}

\footnotetext{
${ }^{a} 8$ samples, concentration levels 5, 10, and $20 \mu \mathrm{g} \mathrm{L}{ }^{-1}$.

${ }^{\mathrm{b}}$ Informed value: $0.5 \mu \mathrm{g} \mathrm{g}^{-1}$.

c 10,20 , and $30 \mu \mathrm{g} \mathrm{L} \mathrm{L}^{-1}$.

${ }^{\mathrm{d}}$ Recommended characteristic mass: $3 \mathrm{pg}$.
}

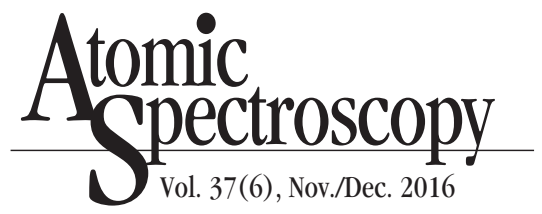

$=3$ sblank, $\mathrm{n}=10 / \mathrm{s}$ and LOQ $=$ 10 sblank, $\mathrm{n}=10$ / $\mathrm{s}$.

Sensitivity was evaluated by calculating the characteristic mass, which was $(4.5 \pm 0.4 \mathrm{pg})$ and when compared with the recommended value ( $3 \mathrm{pg}$ ) is considered appropriate. This mass value is slightly higher and allowed for a wider working range up to 50.0. By comparison, Quinaia and Nobrega (33) determined $\mathrm{Cr}$ in milk by GFAAS obtaining a characteristic mass of $7.8 \mathrm{pg}$. The relative standard deviations obtained by the authors of this study for three different concentrations were within acceptable values of precision, not exceeding $11.8 \%$ and $7.8 \mathrm{pg}$. The concentration of $\mathrm{Cr}$ in the certified reference material SRM 8435 Whole Milk Powder was only informed value; however, the value obtained was very close to the value reported, indicating that the accuracy of the present method is appropriate.

\section{Analytical Application}

An optimized method was applied to the determination of $\mathrm{Cr}$ in 17 samples obtained at a local market. The analysis results of the milk and similar baby food samples are listed in Table VIII. For the analyzed samples, the $\mathrm{Cr}$ concentrations were in the range of 0.042 to $1.900 \mu \mathrm{g} \mathrm{g}^{-1}$, and 0.092 to 0.449 $\mu \mathrm{g} \mathrm{g}^{-1}(\mathrm{n}=3)$ for whole milk, 0.098 $\mu \mathrm{g}^{-1}$ for milk drink $(\mathrm{n}=1), 0.042$ to $0.191 \mu \mathrm{g}^{-1}$ for skimmed milk, $0.047 \mu \mathrm{g}^{-1}$ to $0.131 \mu \mathrm{g} \mathrm{g}^{-1}$ for infant formula $(n=7), 0.140$ and $0.154 \mu \mathrm{g}$ $\mathrm{g}^{-1}$ for soy food and soy infant formula ( $\mathrm{n}=2$ ), 1.15 to $1.90 \mu \mathrm{g} \mathrm{g}^{-1}$ for goat's milk $(\mathrm{n}=2)$. The $\mathrm{Cr}$ content was higher in the goat milk sample powder and lower in a skim milk sample. Comparative studies, such as by Güler (34), reported a Cr concentration of $0.77 \pm 0.08 \mu \mathrm{g} \mathrm{g}^{-1}$ (dry basis) in a raw goat milk sample by ICP-OES after microwave digestion (34). In the work of these authors, the $\mathrm{Cr}$ content in goat milk samples are much lower than those 
observed in the present study (1.15 and $1.90 \mu \mathrm{g} \mathrm{g}^{-1}$ ). Saracoglu et al. (35) found $\mathrm{Cr}$ concentrations in the range 2.02 to $68.8 \mu \mathrm{g} \mathrm{g}^{-1}$ in 19 infant formula samples analyzed by GFAAS after microwave digestion (35). By comparison, the values for infant formula obtained in the present work were very low, between 0.047 to $0.151 \mu \mathrm{g} \mathrm{g}^{-1}$.

\section{CONCLUSION}

In this study, a fast method is proposed to determine $\mathrm{Cr}$ in milk and similar infant food samples using slurries and liquid samples. The slurries preparation process is very simple and consists in a sonication of the powdered samples diluted in ultrapure water for 10 minutes. Chemical modification was very important to stabilize the analyte and the use of Rh (permanent modifier) permitted the direct determination of chromium in undigested milk and similar food samples. The multivariate optimization

TABLE VIII

Chromium Concentrations in Milk and Similar Baby Foods

\begin{tabular}{ll}
\hline Samples & $\begin{array}{c}\text { Concentrations } \\
\left(\mu \mathrm{g} \mathrm{g}^{-1}\right), \\
\mathrm{n}=3 \mathrm{Samples}\end{array}$ \\
\hline Milk drink M3 & $0.098 \pm 0.010$ \\
Whole milk IE1 & $0.449 \pm 0.076$ \\
Whole milk I5 & $0.105 \pm 0.013$ \\
Whole milk I6 & $0.092 \pm 0.004$ \\
Skim milk D2 & $0.191 \pm 0.015$ \\
Skim milk D1 & $0.042 \pm 0.006$ \\
Infant formula F1 & $0.047 \pm 0.021$ \\
Infant formula F2 & $0.064 \pm 0.004$ \\
Infant formula DE1 & $0.076 \pm 0.017$ \\
Infant formula DE2 & $0.131 \pm 0.054$ \\
Infant formula F5 & $0.114 \pm 0.006$ \\
Infant formula F6 & $0.101 \pm 0.008$ \\
Infant formula F8 & $0.110 \pm 0.010$ \\
Infant soy formula FS2 & $0.140 \pm 0.007$ \\
Soy food S1 & $0.154 \pm 0.018$ \\
Goat milk C1 & $1.900 \pm 0.600$ \\
Goat milk C2 & $1.150 \pm 0.120$ \\
\hline
\end{tabular}

approach was an adequate tool to obtain optimal conditions. The figures of merit were satisfactory, and there was good agreement with the NIST SRM 8435 Whole Milk Powder certified sample. It was found that the $\mathrm{Cr}$ concentration in some goat milk samples was much higher than in whole milk, soy-based drink samples, and in an infant formula milkbased drink.

The results of this study show that the method proposed is unique and can be used for chromium (and probably other chemical elements) concentrations in various kinds of milk and similar samples by GFAAS with a simple sonication in ultrapure water.

\section{ACKNOWLEDGMENT}

The authors are grateful for the financial support and scholarships provided by the Conselho Nacional de Desenvolvimento Científico e Tecnológico (CNPq), Coordenação de Aperfeiçoamento de Pessoal de Nivel Superior (CAPES), and the Fundação de Amparo à Pesquisa do Estado de Minas Gerais (FAPEMIG). C. C. Nascentes is grateful to CNPq for the research grant.

\section{Received March 9, 2016.}

\section{REFERENCES}

1. G. Vas and K. Vékey, J. Mass Spectrom. 39, 233 (2004).

2. C.S. Kira and V.A. Mayara, Food Chem. 100, 390 (2007).

3. M.A. De La Fuente, G. Guerrero, and M. Juárez, J. Agric. Food Chem. 43, 2406 (1995).

4. M.D. Mingorance, M.L. Pérezvazquez, and M Lachica, Microwave J. Anal. At. Spectrom. 8, 858 (1993).

5. A. Ikem, A. Nwankwoala, S. Odueyungbo, K. Nyavor, and N. Egiebor, Food Chem. 77, 439 (2002).
6. E. Coni, A. Bocca, P. Coppolelli, S. Caroli, C. Cavallucci, and M. T. Marinucci, Food Chem. 57, 253 (1996).

7. E. Wieteska, A. Lióek, and A. Drzewínska, Anal. Chim. Acta 330, 251 (1996).

8. P. Mader, J. Szákova, and D. Miholová, Analysis 26, 121 (1998).

9. F.A. Chmilenko, and A.N. Baklanov, J. Anal. Chem. 54, 6 (1999).

10. W. Mertz, Physiol. Rev. 49, 163 (1969).

11. K.N. Jeejebhoy, R.C. Chu, E.B. Marliss, G.R. Greenberg, and A. Bruce-Robertson, Am. J. Clin. Nutrit. 30, 531 (1977).

12. R.A. Anderson, In: Proceedings of Alltech's 10th Annual Symposium, Biotechnology in the Feed Industry, Lyons P., Jacques K. A. (eds.), Nottingham University Press, UK, pp. 267-274 (1994).

13. R.A. Anderson, Regul. Toxicol. Pharmacol. 26, S35 (1997a).

14. R.A. Anderson, J. Am. College Nutr. 16, 404 (1997b).

15. R.A. Anderson, and M.M. Polansky, Biol. Trace Elem. Res. 3, 1 (1981).

16. R.A. Anderson, and A.S. Kozlowski, Am. J. Clin. Nutr. 41, 574 (1985).

17. R.A. Anderson, Diabetes and Metabol. 26, 22 (2000).

18. M.B. Rabinowitz, H.C. Gonick, S.R. Levine, and M.B. Davidson, Biol. Trace Elem. Res. 5, 449 (1983).

19.A.S. Abraham, M. Sonnenblick, and M. Eini, The action of chromium on serum lipids and on atherosclerosis in cholesterol-fed rabbits. Atherosclesosis 42, 185 (1982a).

20. G.N. Schrauzer, K.P. Shresta, and T.B. Molenaar, S. Mead, Biol. Trace Elem. Res. 9, 79 (1986).

21. A. Pechova, and L. Pavlata, Vet. Med., 52, 1 (2007).

22. F. Dubois, and F. Belleville, Pathologie-Biologie 39, 801 (1991).

23. R.A. Anderson, N.A. Bryden, K.Y. Patterson, C. Veillon, M.B. Andon, and P.B. Moser-Veillon, Am. J. Clin. Nutr. 57, 519 (1993).

24. J. Kumpulainen, J. Lehto, P. Koivis- 


\section{A Spectroscopy $_{\text {pec }}^{\text {tomich }}$ \\ $\bigcirc$ Vol. 37(6), Nov./Dec. 2016}

toinen, M. Uusitupa, and E. Vuori, Sci. Tot. Environm. 31, 71 (1983).

25. C.E. Casey, and K.M. Hambridge, Br. J. Nutr. 52, 73 (1984).

26. P.C.P. Lara, J.N. Silveira, W.B. Neto, M.A. Beinner, and J.B.B. da Silva, J. Chem. Pharm. Res. 7, 1900 (2015)

27. National Research Council of Canada, in Recommended Dietary Allowances, 10th ed., National Academic Press, Washington, p. 10-23, 1989.

28. J.B.B. da Silva, M.B.O. Giacomelli, and I.G. Souza, Microchem. J. 60, 249 (1988).

29. H.J.F. Fabrino, J.N. Silveira, W. Borges Neto, M.A. Beinner, and J.B.B. da Silva, J. Anal. Toxicol. 35, 571. (2011).

30. H.J.F. Fabrino, J.N. Silveira, W. Borges Neto, and J.B.B. da Silva, Anal. Letters 43, 5085 (2010).

31. H.J.F. Fabrino, W. Borges Neto, S.S.O. Borges, A. Goes, and J.B.B. da Silva, At. Spectrosc. 25, 227 (2007).

32. Statistica 6.0 for Windows, StatSoft, Inc. (2001) 2300 East 14th Street, Tulsa, OK 74104, USA.

33. S.P. Quináia, and J.A. Nóbrega, Quím. Nova, 23, 185 (2000).

34. Z. Güller, and S. Rumin. Res. 71, 130 (2007).

35. S. Saracoglu, K.O. Saygi, O.D. Uluoglu, M. Tuzen, and M. Soylak, Food Chem. 105, 280 (2007). 